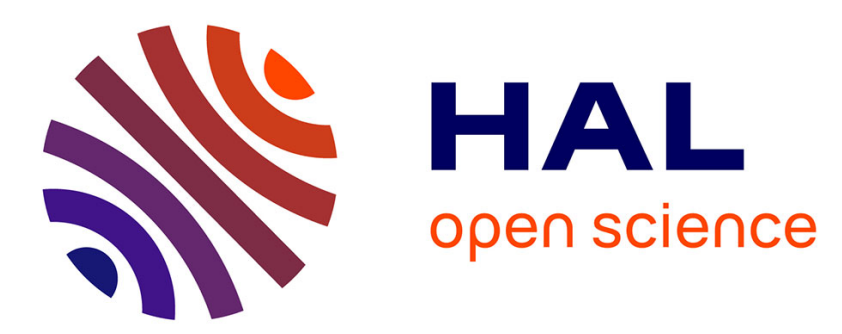

\title{
14-Year Outcomes of Coronally Advanced Flap for Root Coverage: Follow-up from a Randomized Trial
}

\author{
Giovanpaolo Pini Prato, Roberto Rotundo, Debora Franceschi, Francesco \\ Cairo, Pierpaolo Cortellini, Michele Nieri
}

\section{- To cite this version:}

Giovanpaolo Pini Prato, Roberto Rotundo, Debora Franceschi, Francesco Cairo, Pierpaolo Cortellini, et al.. 14-Year Outcomes of Coronally Advanced Flap for Root Coverage: Follow-up from a

Randomized Trial. Journal of Clinical Periodontology, 2011, 38 (8), pp.715. 10.1111/j.1600051X.2011.01744.x . hal-00647406

\section{HAL Id: hal-00647406 \\ https://hal.science/hal-00647406}

Submitted on 2 Dec 2011

HAL is a multi-disciplinary open access archive for the deposit and dissemination of scientific research documents, whether they are published or not. The documents may come from teaching and research institutions in France or abroad, or from public or private research centers.
L'archive ouverte pluridisciplinaire HAL, est destinée au dépôt et à la diffusion de documents scientifiques de niveau recherche, publiés ou non, émanant des établissements d'enseignement et de recherche français ou étrangers, des laboratoires publics ou privés. 


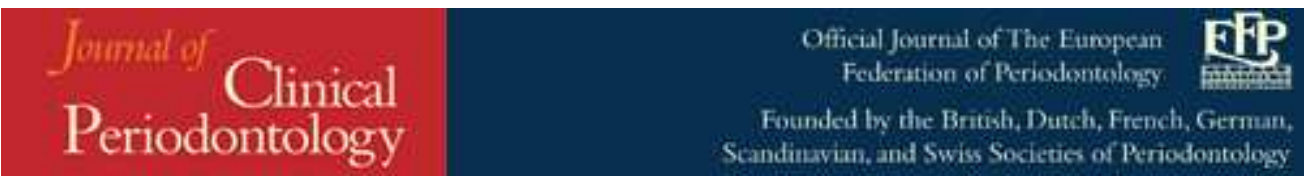

\section{4-Year Outcomes of Coronally Advanced Flap for Root Coverage: Follow-up from a Randomized Trial}

\begin{tabular}{|r|l|}
\hline Journal: & Journal of Clinical Periodontology \\
\hline Manuscript ID: & CPE-12-10-3025.R2 \\
\hline Manuscript Type: & Original Article Clinical Periodontology \\
\hline Date Submitted by the & 09-Apr-2011 \\
\hline Complete List of Authors: & $\begin{array}{l}\text { Pini Prato, Giovanpaolo; university of florence, periodontology } \\
\text { Rotundo, Roberto; University of Florence, Florence, Italy, } \\
\text { 1Department of Periodontology } \\
\text { Franceschi, Debora; University of Florence, Florence, italy, } \\
\text { 1Department of Periodontology } \\
\text { Cairo, Francesco; University of Florence, Florence, Italy, } \\
\text { 1Department of Periodontology } \\
\text { Cortellini, Pierpaolo; 2Accademia Toscana di Ricerca } \\
\text { Odontostomatologica (ATRO) } \\
\text { Nieri, Michele; University of Florence, Periodontology }\end{array}$ \\
\hline \hline Topic: & Treatment \\
\hline Main Methodology: & $\begin{array}{l}\text { Gingival recession, coronally advanced flap, randomized controlled } \\
\text { trial, long term, statistical interaction }\end{array}$ \\
\hline \hline & \begin{tabular}{l} 
Clinical Trial \\
\hline Mords
\end{tabular} \\
\hline \hline
\end{tabular}

\section{SCHOLARONE Manuscripts}




\title{
14-Year Outcomes of Coronally Advanced Flap for Root Coverage:
}

\section{Follow-up from a Randomized Trial}

Pini Prato Giovanpaolo ${ }^{1}$, Rotundo Roberto ${ }^{1}$, Franceschi Debora ${ }^{1}$, Cairo Francesco ${ }^{1}$, Cortellini Pierpaolo $^{2}$, Nieri Michele ${ }^{1}$

${ }^{1}$ Department of Periodontology, University of Florence, Florence, Italy

${ }^{2}$ Accademia Toscana di Ricerca Odontostomatologica (ATRO)

Running title: Long-term root coverage

Key words: gingival recession, coronally advanced flap, randomized controlled trial, long term, statistical interaction

\author{
Address for correspondence: Pini Prato Giovanpaolo \\ viale Matteotti,11 - 50121 - Florence, Italy \\ e-mail: gpinipr@tin.it
}

Conflict of interest: The authors declare that there are no conflicts of interest in this study.

Source of funding: No external funding, apart from the support of the authors' institutions, was available for this study. 


\begin{abstract}
Trial design: This long-term 14-year-randomized split-mouth study aimed at evaluating (1) the outcomes of two different methods of root surface modifications (root surface polishing vs. rootplaning) used in combination with coronally advanced flap (CAF) and (2) the long-term results of CAF performed for the treatment of single gingival recessions.
\end{abstract}

Methods: Ten patients with similar bilateral recessions $\geq 2 \mathrm{~mm}$ were selected for a split-mouth randomized design study. Exposed root surfaces were assigned to receive polishing (test sites) or root planing (control sites). A multilevel model was used to analyze data at 3 months, 1,5 and 14 years.

Results: One patient dropped-out after 1 year. At 14 years recession depth was 0.9 (1.2) mm for test sites and $0.9(0.9) \mathrm{mm}$ for control sites. The interaction between treatment and keratinized tissue (KT) was significant $(\mathrm{p}=0.0035)$. Recession depths increased slightly over time $(\mathrm{p}=0.0006)$ in both groups.

Conclusions: This study shows that during a long-term follow-up, gingival recession recurred in $39 \%$ of the treated sites following CAF procedure.

\title{
CLINICAL RELEVANCE
}

Rationale for the study: To verify the long-term outcomes of root planing versus root surface polishing used in combination with coronally advanced flap procedure for the treatment of single gingival recessions 
Principal findings: Gingival recession depths tend to increase following coronally advanced flap during a 14 year follow-up period. Interaction was found between treatment and baseline Keratinized Tissue (KT).

Practical implications: The amount of baseline KT could influence the choice of treatment. An apical shift of the gingival margin occurs in the long term follow-up period. 


\section{INTRODUCTION}

Coronally advanced flap (CAF) is one of the most reliable techniques for the treatment of single gingival recessions and different surgical flap designs have been proposed over time increasing the possibility of achieving complete root coverage (Cairo et al. 2008; Chambrone et al. 2010).

A prerequisite for root coverage is the treatment/modification of the exposed root surface using different mechanical and/or chemical approaches. Root planing is still being used to remove the microbial biofilm minimizing cementum toxicity (Bertrand \& Dunlap 1988), to smoothe irregularities and grooves on exposed root surface (Wennstrom 1996) and to remove root caries lesions (Fourel et al. 1982; Miller et al. 1983). Vigorous planing has also been suggested to reduce the convexity of the root and the mesio-distal distance between periodontal spaces (Holbrook \& Ochsenbein 1983) thus improving the possibility of obtaining a greater reduction of the recession. However, Saletta et al. (2005) have demonstrated that while strong root planning (40 strokes) does not modify root curvature it does minimally reduce (3\%) the mesio-distal dimensions of the root surface and slightly flattens $(6 \%)$ the root surface. It should be also considered that most of Miller Class I and II gingival recessions are associated with tooth brushing trauma in patients with high levels of oral hygiene, clinically healthy gingiva and clean root surfaces. The role of mechanical instrumentation of the exposed root seems questionable in these patients, (Wennström 1996) and a more conservative approach could be considered. A previous randomized controlled clinical study (RCT) (Pini Prato et al. 1999) compared two mechanical treatments of shallow $(<3 \mathrm{~mm}$ ) gingival recessions associated with CAF: root-planing with curettes versus polishing with rubber cup and prophylaxis paste. At the 3 months re-evaluation the difference in terms of recession reduction between the test and control sites was not statistically different and residual dental hypersensitivity was present in two sites treated with root planing. More recently, a RCT (Zucchelli et al. 2009) was conducted to compare the efficacy of hand and 
ultrasonic instrumentation of the root associated with the CAF approach. The results showed that both treatments were equally effective in terms of root coverage and clinical attachment level (CAL) gain 6 months after surgery.

In the past, chemical conditioning of the exposed cementum (citric acid, tetracycline $\mathrm{HCL}$, etc.) was suggested to improve the clinical and histological outcomes of the treatment of gingival recessions. Chemical agents were used to remove the smear layer produced by root instrumentation (Liu \& Solt 1980), to expose the collagen fibrils of the dental matrix facilitating the formation of a new connective attachment (Selvig et al. 1981; Polson \& Proye 1982) and to eliminate cytopathic material on the exposed root that could inhibit fibroblast growth (Olson et al. 1985). However, systematic reviews (Roccuzzo et al. 2002; Oates et al. 2003) have shown that sites treated with root planing alone or with combined chemical/mechanical treatment do not show significant differences in terms of root coverage.

Although a large number of clinical trials have been published on the treatment of localized gingival recessions, few data are available on the long-term results of these procedures. Leknes et al. (2005) in a long-term RCT reports that CAF is a reliable technique for the treatment of recessions in terms of root coverage, probing depth and CAL gain. In particular, the results are stable at short follow-up (6-12 months) but long-term (6 years) stability seems to be critically dependent on the recall visits and re-instruction in the use of non-traumatic brushing practices. Using the same population of a previous study (Pini Prato et al. 1999), this long-term 14-yearrandomized split-mouth study aimed at evaluating (1) the outcomes of two different methods of root surface modifications (root-planing vs. root surface polishing) used in combination with CAF and (2) the long-term results of CAF performed for the treatment of single gingival recessions.

\section{METHODS}




\section{Study Population}

The study population comprised the group published in a previous short-term split-mouth randomized clinical trial conducted to investigate the potential benefit of root instrumentation or root polishing in the treatment of single gingival recessions with the Coronally Advanced Flap (CAF) procedure 3 months after surgery (Pini Prato et al. 1999). Ten patients were selected among individuals referred to the Department of Periodontology of University of Siena Dental School. An a priori sample size calculation was not performed.

Information on this study is summarized below.

The entry criteria used were: 1) non-compromised systemic health and no contraindications for periodontal surgery; 2) presence of maxillary bilateral buccal recessions $\geq 2 \mathrm{~mm}$ classified as Miller's Class I or II; 3) difference in depth of the gingival recession between right and left site $\leq 1$ $\mathrm{mm}$ and difference in clinical attachment level $\leq 2 \mathrm{~mm}$; 4 ) identifiable cement-enamel junction (CEJ); 5) tooth vitality and absence of grooves, irregularities, caries, or restorations in the area to be treated; 6) no periodontal surgical treatment during the previous 24 months on the involved sites; 7) full-mouth plaque score (FMPS) $<20 \%$ and full mouth bleeding score (FMBS) $<20 \%$; and 8 ) absence of plaque and bleeding on probing at the selected sites.

The ten patients enrolled in this study received oral hygiene instructions to eliminate habits related to the etiology of the recessions.

\section{Clinical measurements}

The following measurements were taken by one investigator (GPP) using a PCP UNC 15 periodontal probe at baseline:

Recession depth (REC) on the mid-buccal site

Probing Depth (PD) on the mid-buccal site

Clinical Attachment Level (CAL) calculated as PD + Rec 
Keratinized Tissue (KT) width: distance between gingival margin (GM) and mucogingival junction (MGJ)

Anatomical crown length (IM-CEJ): distance between incisal margin (IM) and cement-enamel junction (CEJ)

Dentin hypersensitivity (DH): present or absent.

\section{Randomization}

A split-mouth design was used. The sites were randomly assigned to 2 treatment groups (test and control) by tossing a coin (PC) immediately prior to surgery. In the test group, exposed root surfaces were treated by polishing before flap elevation, using a rubber cup and a prophylaxis paste for 60 seconds under local anesthesia. Polishing was also performed in the intrasulcular area. Immediately after polishing, the root surface was washed with water spray for 60 seconds. In the control group exposed root surfaces were treated by means of root planing, using curettes under local anesthesia. Root planing was also performed in the intrasulcular area. Immediately after instrumentation the treated root surfaces were washed for 60 seconds with water spray.

\section{Surgical procedures}

Both groups underwent CAF procedure performed by the same operator (GPP). In 9 patients homologous contralateral teeth were treated while a canine and a contralateral lateral incisor were treated in patient number 4. A trapezoidal flap was designed using one intrasulcular and two oblique releasing incisions. The full- split thickness pedicle flap was then elevated. Care was taken to reduce flap tension and facilitate the passive coronal displacement of the gingival margin. The 
papillae adjacent to the gingival recession were carefully de-epithelialized and the flap was then coronally displaced and sutured.

\title{
Post-surgical protocol
}

Patients were instructed to avoid any mechanical trauma and tooth brushing for 3 weeks in the surgical area. Chlorhexidine rinses were prescribed twice daily for 1 minute. Sutures were removed seven days after surgery and prophylaxis was performed. About 3 weeks after surgery, all patients were instructed to resume mechanical tooth cleaning. The patients were recalled 3 months after surgery and periodontal measurements were repeated.

\section{Follow up 3 months-14 years}

The 10 patients of the previous article were enrolled in the present study and followed for a long period of time.

During the 14 year observation period, patients were recalled for 1, 5 and 14 year follow up visits and they complied with the program of supporting periodontal care. They were also re-called every 6 months for professional re-instruction and prophylaxis.

The same baseline and 3-month periodontal measurements (Rec, PD, CAL, IM-GM, IM-MGJ, and GM-MGJ) were repeated by the same investigator (GPP) who was not blinded to the treatment and who always used the same periodontal probes.

\author{
Statistical analysis \\ Quantitative data were summarized as means (standard deviation) and qualitative data were \\ summarized as frequency (percentage).
}


Differences in recession depth between the two treatment groups were analyzed using a multilevel model at three levels: Patient, Site and Occasion. Occasion refers to the measurements performed at 3 months, 1, 5 and 14 years. Explicative variables were: treatment (Polishing vs. Root Planing), baseline recession depth, baseline Keratinized Tissue width, Time ( 3 months, 1 year, 5 years and 14 years). Interactions Treatment $x$ Time, Treatment $x$ Recession depth and Treatment $x$ KT were tested. Non-significant interactions were excluded from the model. Time was used as a continuous variable. The software was MLwiN version 2.02 (c) Multilevel Models Project Institute of Education, University of Bristol. The algorithm used to fit the model was the IGLS (Iterative Generalised Least Square).

Differences in hypersensitivity $(\mathrm{DH})$ and $\mathrm{CRC}$ at 14 years between the treatment groups were analyzed using the McNemar test.

\section{RESULTS}

Out of 10 patients, one patient dropped out 1 year later because she moved to another country. In the test group (Polishing) recession depth was 0.6 (0.7) $\mathrm{mm}$ at 1 year (in 1997), 0.9 (1.1) $\mathrm{mm}$ at 5 years (in 2001) and $0.9(1.2) \mathrm{mm}$ at 14 years (in 2010). In the control group (Root planing) recession depth was $0.5(0.6) \mathrm{mm}$ at 1 year, $0.7(0.8) \mathrm{mm}$ at 5 years and $0.9(0.9) \mathrm{mm}$ at 14 years. CRC was quite stable over time in both sides. Eight sites, 5 in the test and 3 in the control group showed complete root coverage at 14 years. On the other hand, one site (root planing) showing $\mathrm{CRC}$ at 3 months developed a new recession at 14 years while one site (Polishing) and one site (Root Planing) that showed a recession at 3 months developed a CRC at 14 years.

The amount of KT decreased slightly over time in both sides.

Dental hypersensitivity disappeared in both sides one year after treatment, while it recurred in 3 sites of each group at the 14 year follow up. (Table 1). 
No side effects occurred during the follow-up period.

$\underline{\text { Inferential statistics }}$

The multilevel model for recession depth is shown in Table 2. The interaction between treatment and KT is significant $(p=0.0035)$. In fact, in cases of $3 \mathrm{~mm}$ of baseline $\mathrm{KT}$, the 2 treated groups showed no difference in terms of recession depth during the follow-up observations. Nevertheless, comparing the two treatments, the greater the baseline amount of KT, the lower the final recession depth in the test group (polishing), while in the control sites (root planing) the lower the baseline amount of KT, the lower the final recession depth (Fig. 1).

Taking into consideration $3 \mathrm{~mm}$ of baseline $\mathrm{KT}$ as the point of indifference between the two treatments, figures 2 and 3 show the trend of gingival recession depth variation within the 2 groups over time, for sites with $\mathrm{KT}<3 \mathrm{~mm}$ and sites with $\mathrm{KT} \geq 3 \mathrm{~mm}$.

Recession depth increased slightly over time $(p=0.0006)$ in both the test and control sites. Seven sites ( 4 in the Polishing group and 3 in the Root Planing group) showed an increased recession depth from 3 months to 14 years.

At 14 years there was no difference in dental hypersensitivity or CRC between the two groups ( $p=1$ and $p=0.8308$, respectively).

One treated case is reported in figures 4-8.

\section{DISCUSSION}

Using the same patients of the previous study (Pini Prato et al. 1999), the present 14-year longterm randomized clinical study aimed at evaluating: 1) the outcomes of two different methods of root surface treatments (root planing vs. root surface polishing) used in combination with CAF; and 2) the long term results of CAF performed for the treatment of single gingival recessions.

\section{Outcomes of root surface treatment: root planing versus root surface polishing}


Only a few studies discuss different approaches for treating exposed root surfaces associated with gingival recession for root coverage procedures. Oles et al. (1988) compared the efficacy of scaling/polishing, root planing, and sodium hypochlorite root conditioning associated with a laterally positioned flap. Three months later, the results of that study did not show any statistical difference in the clinical outcomes among the 3 treated groups.

More recently, another randomized controlled split-mouth clinical study (Zucchelli et al. 2009) was conducted to compare the efficacy of hand and ultrasonic instrumentation in combination with CAF in 11 patients with bilateral Miller class I and II single recessions. The control root surfaces were planed with curettes while the test group roots were instrumented with ultrasonic piezoelectric devices. Hand and ultrasonic root instrumentation proved equally effective in terms of root coverage and CAL gain at 6 months post-surgery.

In the present study, a multilevel statistical model was set up considering baseline recession depth, baseline keratinized tissue width, treatment, and occasions as explicative variables; recession depth was the outcome variable. Interaction effects were considered in the model. Interaction is defined as "a process in which the combined effects of two or more variables are greater than the sum of their individual effects" (Lang \& Secic 2006). In this study, treatment "per se" (polishing versus root planing) did not show differences in terms of final recession depth; on the other hand the treatment combined with the baseline amount of KT showed a significant effect. In fact, the two approaches showed different trends: polishing (test group) resulted in a greater recession reduction in the presence of a greater KT width, while root planing (control group) showed a greater recession reduction in sites with a smaller amount of KT. However, these observed clinical outcomes following the 2 root surface therapies appear difficult to explain and therefore further studies are needed. 
A post-hoc power calculation was reported in the previous short term study publication (Pini-Prato et al. 1999). The power to detect a difference in change of $0.5 \mathrm{~mm}$ at a significant level of $\alpha=0.05$ was $67 \%$. In this long term study a significant difference in interaction terms was found, Therefore, the study has sufficient power to detect this difference. Anyway it is possible that the interaction result is due to chance and in this case a statistical type I error is made.

\section{Long-term results of CAF procedure.}

The present study was also useful in evaluating the long-term outcomes of the coronally advanced flap technique for the treatment of gingival recession defects. Few data are available in the periodontal literature. Leknes et al. (2005) reported a severe recurrence of gingival recession in a 6-year long-term study in sites treated either with CAF alone or with CAF and a bio-resorbable barrier. At 6 years, out of 11 bilateral single recessions only 2 sites treated with barriers and 1 site treated with CAF were still completely covered.

A 3-year case series study (De Sanctis \& Zucchelli 2007) reported an increased amount of keratinized tissue associated with $97 \%$ average root coverage following a modified CAF procedure performed on single-recession defects .

In a 5 year long term evaluation of a case series treated with the envelope type of CAF approach on multiple recessions, Zucchelli \& De Sanctis (2005) reported a slight shift of the gingival margin as compared to 1-year data. In fact, complete root coverage was observed in $88 \%$ of the cases at 1 year, while it decreased to $85 \%$ at 5 years.

Another 5 year long-term comparative study (Pini Prato et al. 2010) on multiple recessions treated with CAF alone or with CAF + Connective tissue graft (CTG) showed a similar trend toward a consistent shift of the gingival margin in the CAF treated sites, while the CAF+CTG treated sites showed a tendency to a coronal shift of the gingival margin. 


\section{1}

The present long-term study performed on single gingival recessions revealed an apical shift of the gingival margin in about $39 \%$ of the treated sites showing a progressive worsening of the gingival recessions during the 14 -year follow-up period. The estimated apical shift was $0.024 \mathrm{~mm}$ per year, on average. This result was statistically significant even if it might not appear relevant from a clinical standpoint. However, a small increase in gingival recession may cause the recurrence of dental hypersensitivity. The observed relapse of the soft tissue defects could be due to a resumption of traumatic tooth brushing habits in patients with high levels of oral hygiene even if they were included in a stringent maintenance protocol with recalls every 4 to 6 months. At each recall visit, the oral hygiene procedures were checked and the patients were re-motivated and reinstructed, if needed. As a consequence of the apical shift of the gingival margin, the dental hypersensitivity that had disappeared in all the treated sites after 1 year, reappeared after 14 years in 6 sites ( 3 patients) that did not show complete root coverage.

Regarding the KT width, the results of this study showed that it tends to decrease over time. These outcomes differ from those reported in other studies where an increased amount of KT occurred after 1 and 5 years (Zucchelli et al. 2005, 2009).

This randomized trial does have some methodological limitations, such as the lack of sample size calculation and blindness. However, it should be considered that this study was conducted back in 1995-1996; CONSORT statements to improve the quality of randomized controlled trials were not available at that time.

In conclusion, root planing and polishing treatments of the exposed root surface used in combination with CAF showed similar outcomes in terms of recession reduction after 14 years. However, considering the baseline amount of $\mathrm{KT}$, polishing seems to be more indicated than root planing in cases of $\mathrm{KT}$ widths greater than $3 \mathrm{~mm}$, while root planing appears to be more appropriate in cases of baseline $\mathrm{KT}$ widths of less than $3 \mathrm{~mm}$. In addition, at 14 years, an apical 
shift of the gingival margin (recession relapse) was found in $39 \%$ of the sites treated with the coronally advanced flap procedure.

2

3 


\section{REFERENCES}

Bertrand, P.M., Dunlap, R.M. (1988) Coverage of deep, wide gingival clefts with free gingival autografts: root planing with and without citric acid demineralization. International Journal of Periodontics and Restorative Dentistry 8, 64-77.

Cairo, F., Pagliaro, U., Nieri, M. (2008) Treatment of gingival recession with coronally advanced flap procedures: a systematic review. Journal of Clinical Periodontology 35: 136-162.

Chambrone, L., Sukekava, F., Araújo, M.G., Pustiglioni, F.E., Chambrone, L.A., Lima, L.A. (2010) Root-coverage procedures for the treatment of localized recession-type defects: a Cochrane systematic review. Journal of Periodontology 81: 452-478.

DeSanctis, M., Zucchelli, G. (2007) Coronally advanced flap: a modified surgical approach for isolated recession-type defects: three-year results. Journal of Periodontology, 34, 262-268.

Fourel, J. (1982) Gingival reattachment on carious tooth surfaces. A 4-year follow-up. Journal of Clinical Periodontology 9: 285-289.

Holbrook, T., Ochsenbein, C. (1983) Complete coverage of the denuded root surface with a One-stage gingival graft. International Journal of Periodontics and Restorative Dentistry 3: 927.

Lang, T.A., Secic, M. (2007) How to report statistics in medicine. American College of Physicians. Philadelphia, Second Edition p. 413

Leknes, K.N., Amarante, E.S., Price, D.E., Boe, O.E., Skavland, R.J., Lie, T. (2005) Coronally positioned flap procedures with or without a biodegradable membrane in the treatment of human gingival recession. A 6-year follow-up study. Journal of Clinical Periodontology 32: 518-529. 
Liu, W.J.L., Solt C.W. (1980) A surgical procedure for the treatment of localized gingival recession in conjunction with root surface citric acid conditioning. Journal of Periodontology $51,505-509$

Miller, P.D. (1983) Root coverage using a free soft tissue autograft following citric acid application. Part II. Treatment of the carious root. International Journal of Periodontics and Restorative Dentistry 3: 38-51.

Oates, T.W., Robinson, M., Gunsolley, J.C. (2003) Surgical therapies for the treatment of gingival recession. A systematic review. Ann Periodontol 8: 303-320

Oles, R.D., Ibbott, C.G., Laverty, W.H. (1988) Effect of root curettage and sodium hypochlorite treatment on pedicle flap coverage of localized recession. Journal of Canadian Dental Association 54: 515-517.

Olson, R.H., Adams, D.F., Layman, D.L. Inhibitory effect of periodontally diseased root extracts on the growth of human gingival fibroblasts. Journal of Periodontology 1985;56:592-596

Pini Prato, G.P., Baldi, C., Pagliaro, U., Nieri, M., Saletta, D., Rotundo, R., Cortellini, P. (1999) Coronally advanced flap procedure for root coverage. Treatment of root surface: root planing versus polishing. Journal of Periodontology 70: 1064-1076.

Pini Prato, G.P., Cairo, F., Nieri, M., Franceschi, D., Rotundo, R., Cortellini, P. (2010) Coronally advanced flap versus connective tissue graft in the treatment of multiple gingival recessions: a split-mouth study with a 5-year follow-up. Journal of Clinical Periodontology 37: 644-650.

Polson, A.M. \& Proye, M.P. (1982) Effects of root surface alterations on periodontal healing. II. Citric acid treatment of the denuded root. Journal of Clinical Periodontology 9:441-454

Roccuzzo, M., Bunino, M., Needleman, I. \& Sanz, M. (2002) Periodontal plastic surgery for treatment of localized gingival recessions: a systematic review. Journal of Clinical Periodontology 29: 178-194. 
Saletta, D., Baldi, C., Nieri, M., Ceppatelli, P., Franceschi, D., Rotundo, R., Cairo, F., Pini Prato, G.P. (2005) Root curvature: differences among dental morphotypes and modifications after mechanical instrumentation. Journal of Periodontology. 76:723-730.

Selvig, K.A., Ririe, C.M., Nilveus, R., Egelberg, J. (1981) Fine structure of new connective tissue attachment following acid treatment of experimental furcation pockets in dogs. Journal of Periodontal Research 16:123-129

Wennström, J.L. (1996) Mucogingival therapy. World Workshop in Periodontics. Annals of Periodontology 1: 671-701.

Zucchelli, G., De Sanctis, M. (2005) Long-term outcome following treatment of multiple Miller class I and II recession defects in esthetic areas of the mouth. Journal of Periodontology 76: 2286-2292.

Zucchelli, G., Mounssif, I., Stefanini, M., Mele, M., Montebugnoli, L., Sforza, N.M. Hand and ultrasonic instrumentation in combination with root-coverage surgery: a comparative controlled randomized clinical trial. J Periodontol 2009: 80: 577-585

Zucchelli, G., Mele, M., Mazzotti, C., Marzadori, M., Montebugnoli, L., De Sanctis, M. Coronally advanced flap with and without vertical releasing incisions for the treatment of multiple gingival recessions: a comparative controlled randomized clinical trial. J Periodontol. 2009;80:1083-94 


\section{FIGURES AND TABLES}

Figure 1. Interaction between treatment and baseline Keratinized Tissue, considering a baseline recession depth of $3 \mathrm{~mm}$.

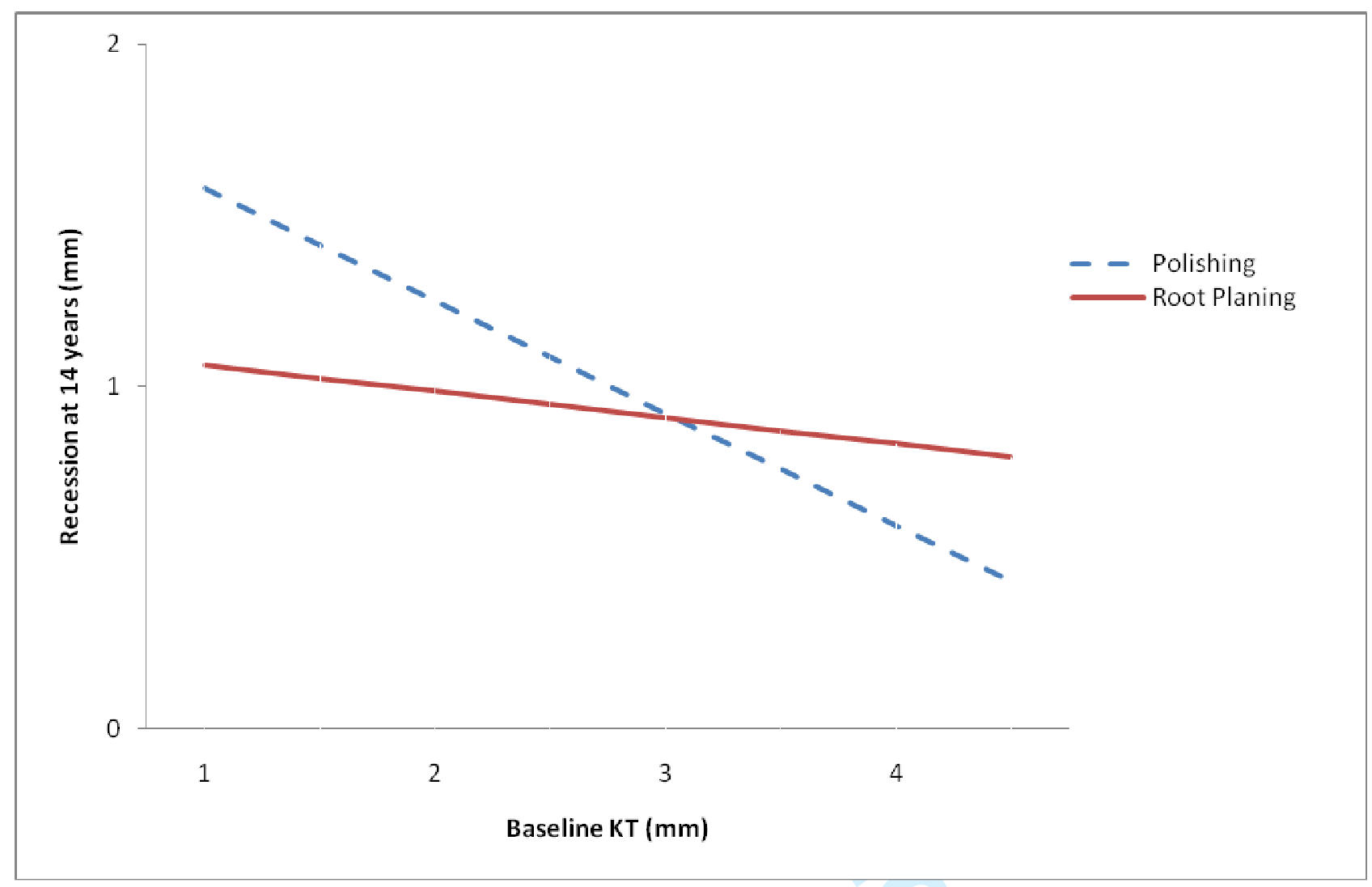


Figure 2. Trend of gingival recession depth in sites with $\mathrm{KT}<3 \mathrm{~mm}$ during the 14 -year follow-up.

\section{Recession depth for baseline $\mathrm{KT}<3 \mathrm{~mm}$}

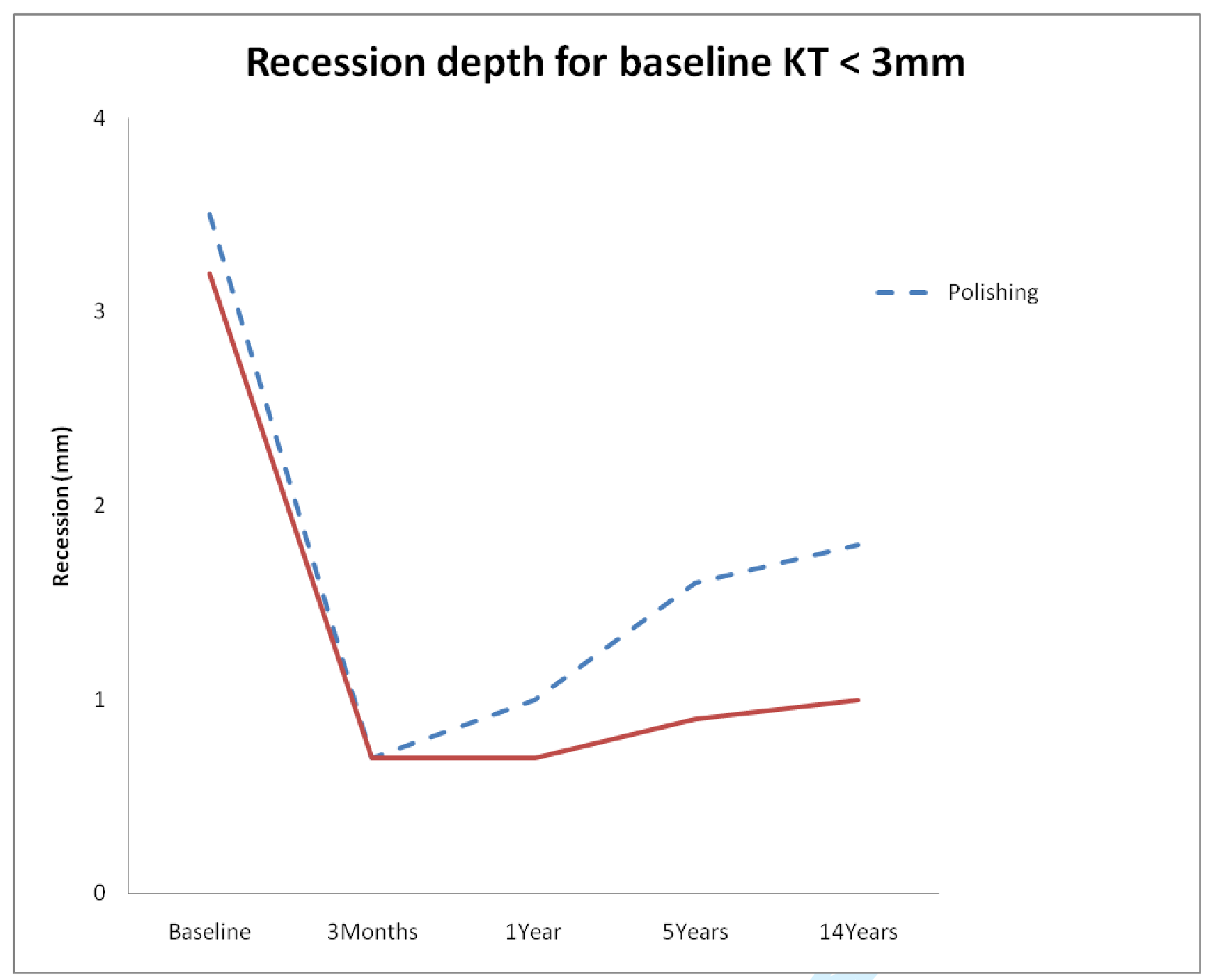


Figure 3. Trend of gingival recession depth in sites with $\mathrm{KT} \geq 3 \mathrm{~mm}$ during the 14-year follow-up.

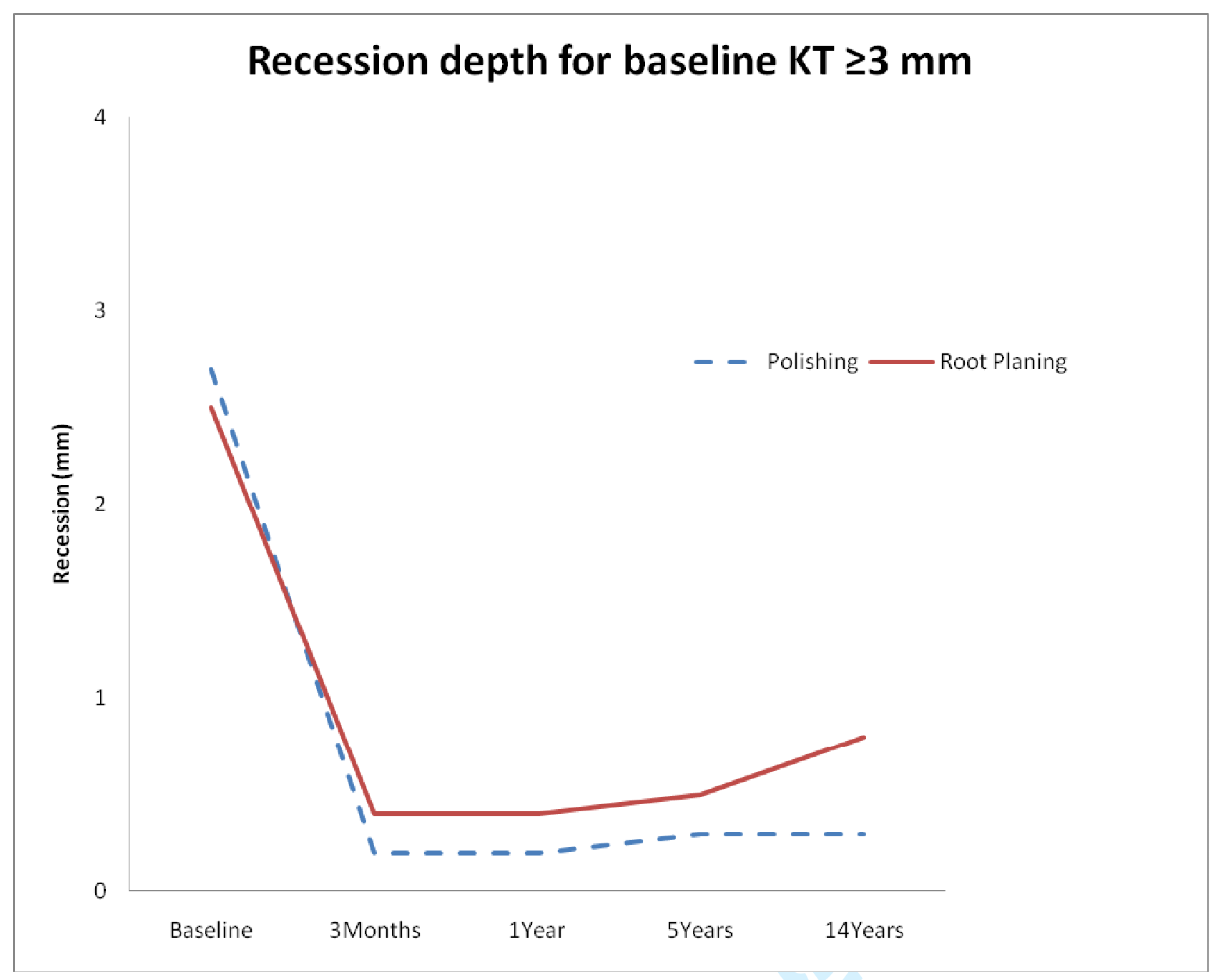


Figure 4. Bilateral recessions on maxillary canines

Figure 5. The exposed roots were randomly treated by rubber cup and prophylaxis paste (left sidetest group) and by sharp curette (right side-control group)

Figure 6. Coronally advanced flaps were performed on both test and control sites in the same surgical session.

Figure 7. Results 1 year after surgery. Complete root coverage was obtained in both the test and control sites.

Figure 8. Results 14 years after surgery. Recession of gingival margin occurred in both sites. 
Table 1. Descriptive statistics.

\begin{tabular}{|c|c|c|c|c|c|c|c|c|c|c|}
\hline & \multicolumn{2}{|c|}{$\begin{array}{l}\text { Baseline } \\
\text { (10 patients) }\end{array}$} & \multicolumn{2}{|c|}{$\begin{array}{l}3 \text { months } \\
\text { (10 patients) }\end{array}$} & \multicolumn{2}{|c|}{$\begin{array}{l}1 \text { year } \\
\text { (10 patients) }\end{array}$} & \multicolumn{2}{|c|}{$\begin{array}{l}5 \text { years } \\
(9 \text { patients })\end{array}$} & \multicolumn{2}{|c|}{$\begin{array}{l}14 \text { years } \\
\text { ( } 9 \text { patients) }\end{array}$} \\
\hline & Polishing & $\begin{array}{l}\text { Root } \\
\text { planing }\end{array}$ & Polishing & $\begin{array}{l}\text { Root } \\
\text { planing }\end{array}$ & Polishing & $\begin{array}{l}\text { Root } \\
\text { planing }\end{array}$ & Polishing & $\begin{array}{l}\text { Root } \\
\text { planing }\end{array}$ & Polishing & $\begin{array}{l}\text { Root } \\
\text { planing }\end{array}$ \\
\hline $\operatorname{Rec}(\mathbf{m m})$ & $3.1(1.1)$ & $2.9(1.0)$ & $\theta .4(0.6)$ & $0.5(0.6)$ & $0.6(0.7)$ & $0.5(0.6)$ & $0.9(1.1)$ & $0.7(0.8)$ & $0.9(1.2)$ & $0.9(0.9)$ \\
\hline KT (mm) & $3.1(1.3)$ & $2.7(1.2)$ & $2.5(1.3)$ & $2.5(1.0)$ & $2.4(1.3)$ & $2.6(0.8)$ & $2.3(1.7)$ & $2.4(1.0)$ & $2.4(1.8)$ & $2.3(1.3)$ \\
\hline PD (mm) & $1.3(0.5)$ & $1.3(0.5)$ & $0.7(0.4)$ & $\theta .7(0.4)$ & $0.7(0.4)$ & $1.0(0.4)$ & $0.8(0.5)$ & $1.0(0.4)$ & $1.0(0.6)$ & $1.0(0.5)$ \\
\hline CRC & - & - & $5(50 \%)$ & $4(40 \%)$ & $4(40 \%)$ & $4(40 \%)$ & $5(56 \%)$ & $4(44 \%)$ & $5(56 \%)$ & $3(33 \%)$ \\
\hline Hypersensitivity & $5(50 \%)$ & $4(40 \%)$ & $\theta(0 \%)$ & $z(20 \%)$ & $0(0 \%)$ & $0(0 \%)$ & $3(33 \%)$ & $2(22 \%)$ & $3(33 \%)$ & $3(33 \%)$ \\
\hline
\end{tabular}

Test=Polishing; Control=Root Planing. Mean (Standard Deviation) for quantitative variables and Frequency (Percentage) for qualitative variables. 
Table 2. Multilevel model for Recession Depth.

$$
\begin{aligned}
\text { Rec }_{i j k}= & b_{0 i j k}+b_{1} \text { Treatment }_{j k}+b_{2} \text { baseline_recession }_{j k}+b_{3} \text { baseline_KT }_{j k}+b_{4} \text { Treatment } x_{\text {baseline_K }} K T_{j k}+b_{5} \\
& \text { Time }_{i j k}+v_{k}+u_{j}+e_{i}
\end{aligned}
$$

\begin{tabular}{|l|l|l|l|}
\hline Term & Estimate & Std Error & $\mathrm{p}$-value \\
\hline Intercept & -0.608 & 0.443 & \\
\hline Treatment (Test=1) $)_{\mathrm{jk}}$ & 0.766 & 0.272 & 0.0049 \\
\hline Baseline Recession ${ }_{\mathrm{jk}}$ & 0.463 & 0.093 & $<0.0001$ \\
\hline Baseline $\mathrm{KT}_{\mathrm{jk}}$ & -0.077 & 0.093 & 0.4077 \\
\hline${\text { Treatment } \mathrm{x} \text { Baseline } \mathrm{KT}_{\mathrm{jk}}}$ & -0.251 & 0.086 & 0.0035 \\
\hline Time & & & \\
\hline$\sigma_{\text {Patient }}^{2}$ & 0.024 & 0.007 & 0.0006 \\
\hline$\sigma_{\text {Site }}^{2}$ & 0.072 & 0.044 & \\
\hline$\sigma^{2}{ }_{\text {Occasion }}$ & 0.016 & 0.022 & \\
\hline
\end{tabular}

$\sigma^{2}=$ Variance; $\mathrm{i}, \mathrm{j}$, $\mathrm{k}$ refer to occasion, site, patient. Treatment is a binary variable with value 1 if test and 0 if control side. Time is a continuous variable in years. Recession and KT are measured in $\mathrm{mm}$. 


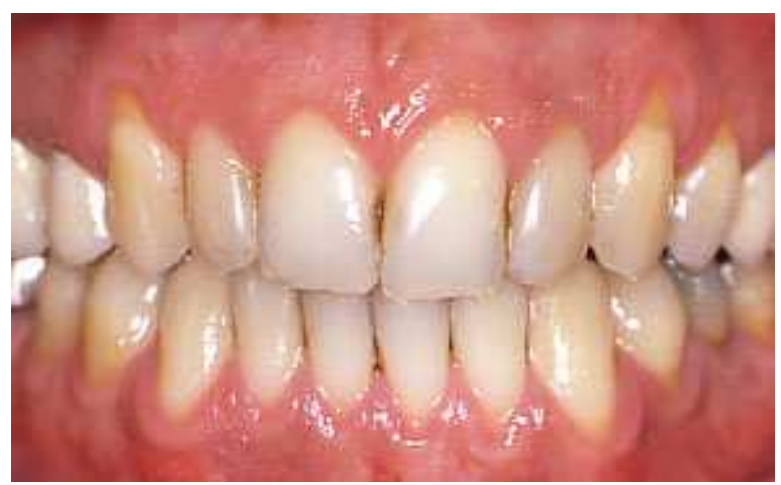

Figure 4. Bilateral recessions on maxillary canines $24 \times 15 \mathrm{~mm}$ (300 x 300 DPI) 
Figure 5. The exposed roots were randomly treated by rubber cup and prophylaxis paste (left sidetest group) and by sharp curette (right side-control group) $28 \times 14 \mathrm{~mm}(300 \times 300 \mathrm{DPI})$ 


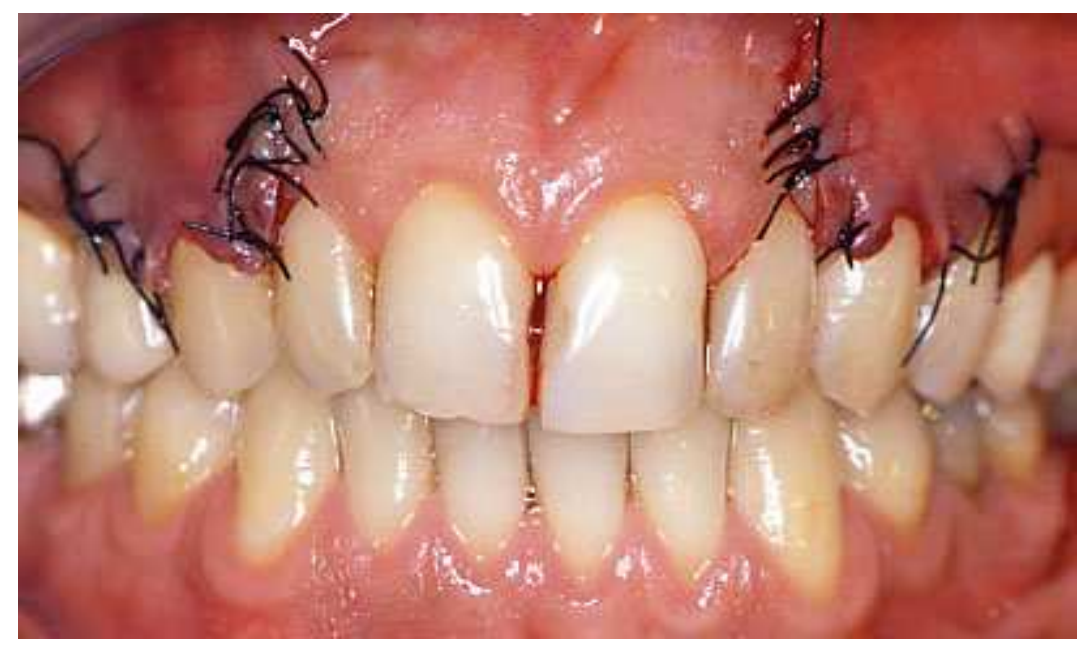

Figure 6. Coronally advanced flaps were performed on both test and control sites in the same surgical session. $34 \times 20 \mathrm{~mm}(300 \times 300 \mathrm{DPI})$ 
Figure 7. Results 1 year after surgery. Complete root coverage was obtained in both the test and control sites. $24 \times 15 \mathrm{~mm}(300 \times 300$ DPI) 


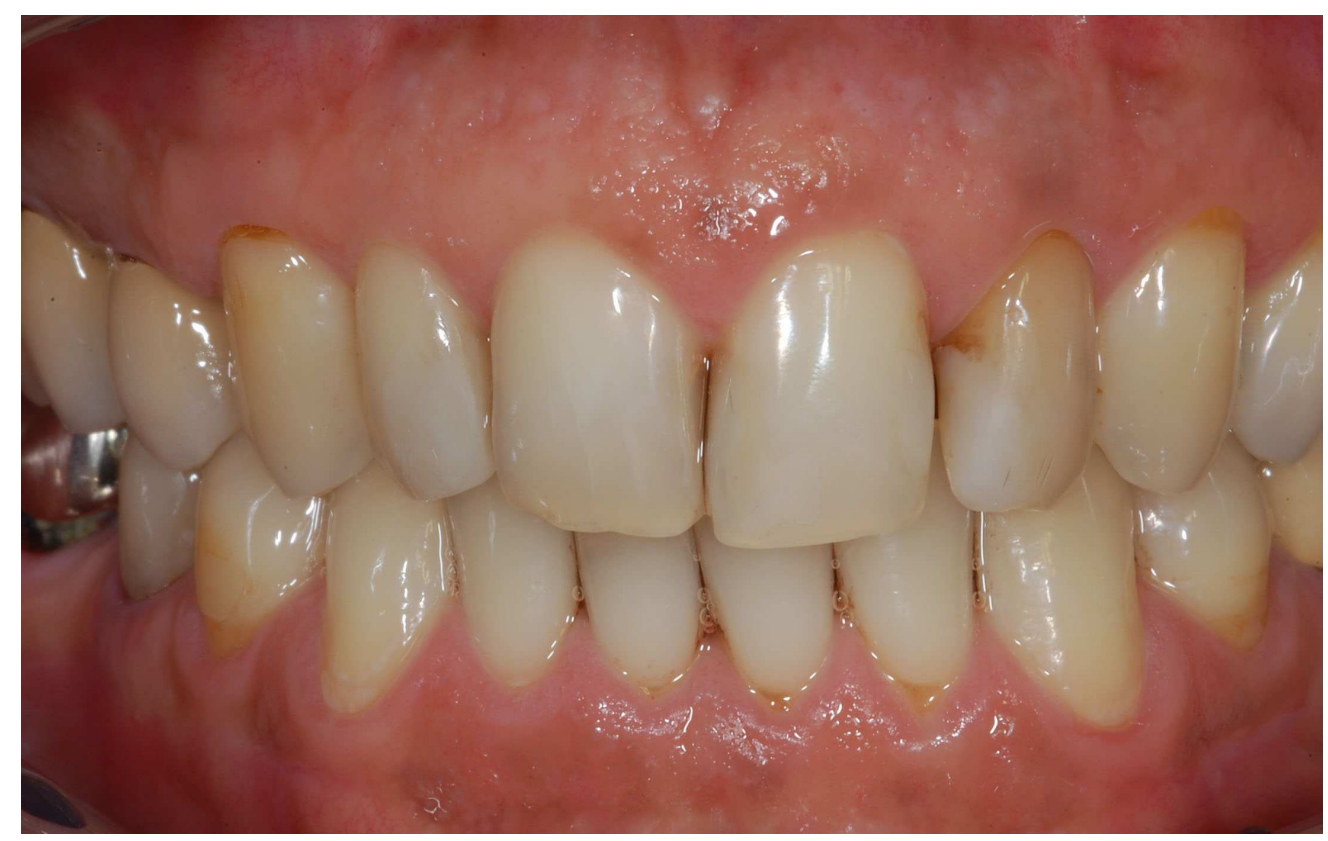

Figure 8. Results 15 years after surgery. Recession of gingival margin occurred in both sites. $186 \times 116 \mathrm{~mm}(300 \times 300 \mathrm{DPI})$ 